\title{
Diverse criteria's-disparate prevalence rates: prevalence of metabolic syndrome by modified NCEP-ATP III and IDF criteria
}

\author{
Shetty S.B ${ }^{1}$, Lalitha $\mathbf{R}^{2}$, Kumar R.A ${ }^{3}$ \\ ${ }^{1}$ Dr. Surekha. B. Shetty, M.D in Internal Medicine, Consultant Diabetologist, ${ }^{2}$ Lalitha R, M.D in Internal Medicine, \\ Consultant Diabetologist, ${ }^{3}$ Anil Kumar R, M.D in Internal Medicine, Consultant Diabetologist, all authors are affiliated \\ with Karnataka Institute of Diabetology, Bangalore, India
}

Address for Correspondence: Dr. Surekha. B. Shetty, Email id: doc.surekha@ gmail.com

\begin{abstract}
Background: Metabolic syndrome is a cluster of metabolic risk factors including central obesity, glucose intolerance, atherogenic dyslipidemia and hypertension. Studies have shown a prevalence of $10-84 \%$ in general population and 5792\% in type 2 diabetic patients. Aims and Objectives: Our study aims to establish the prevalence of metabolic syndrome in diabetic patients at Karnataka Institute of Diabetology, Bangalore. It aims to compare the prevalence using modified NCEP-ATP III and IDF criteria, and also in women and men. Methodology: A cross-sectional study was conducted in 402 (38.6\% women, 61.4\% men) type 2 diabetic subjects. Fasting blood glucose, lipid profile, waist circumference and blood pressure were recorded. Modified NCEP-ATP III and IDF criteria were used to calculate the prevalence of metabolic syndrome. Results: The prevalence of metabolic syndrome was $75.1 \%$ by modified NCEP-ATP III and $68 \%$ by IDF criteria. The prevalence was $94 \%$ and $92 \%$ in women and $62 \%$ and $54 \%$ in men, by modified NCEP-ATP III and IDF criteria respectively. Hypertension was the commonest component in men, and high waist circumference was the commonest component in women. Nearly $50 \%$ had 4 components of metabolic syndrome, $\approx 30 \%$ had 3 components and $\approx 25 \%$ had all the 5 components. Conclusions: The prevalence of metabolic syndrome is very high among diabetic patients. It is higher using modified NCEP-ATP III compared to IDF criteria, especially in men. The prevalence is higher in women, due to central obesity. Hence, all type 2 diabetic patients must be evaluated for metabolic syndrome.
\end{abstract}

Keywords: Atherogenic dyslipidemia, High waist circumference, Hypertension, IDF criteria, modified NCEP-ATP III criteria, Metabolic syndrome, Type 2 Diabetes.

\section{Introduction}

The significance of deranged anthropometric and metabolic status was recognized 250 years ago, when JB Morgagni first described the association between visceral obesity, hypertension, hyperuricemia, atherosclerosis \& obstructive sleep apnea [1]. In 1988, Gerald Raeven further drew attention on the topic when he introduced the concept of insulin resistance in his famous Banting Oration [2]. Since then, there is lot of interest about the concept of "metabolic syndrome", also referred by various synonyms like Insulin Resistance Syndrome, Reaven's Syndrome, Metabolic Syndrome, Syndrome ' $\mathrm{X}$ ' etc. Metabolic Syndrome is a cluster of metabolic risk factors including central

Manuscript received $4^{\text {th }}$ August 2016

Reviewed: $16^{\text {th }}$ August 2016

Author Corrected: $27^{\text {th }}$ August 2016

Accepted for Publication $14^{\text {th }}$ September 2016 obesity, glucose intolerance, hyperinsulinemia, low HDL cholesterol, high triglycerides and hypertension [3]. It is considered as a precursor to various cardiovascular and metabolic diseases, and has been associated with 3-fold risk of CHD [4] \& 5-fold risk of diabetes [5].

The definition of metabolic syndrome has evolved over time. World Health Organization (WHO), National Cholesterol Education Program - Adult Treatment Panel III (NCEP - ATP III), International Diabetes Federation (IDF), American Heart Association (AHA) and other organisations have come up with definition of metabolic syndrome using different parameters. WHO identified insulin resistance as the central cause of metabolic syndrome and hence, insulin resistance was considered 
as the essential criteria for metabolic syndrome. NCEPATP III included hyperglycemia, central obesity, atherogenic dyslipidemia and hypertension as the components, giving equal impetus to all the components. In IDF criteria, central obesity was considered as the essential component of metabolic syndrome [6].

Like most other syndromic conditions, presence of multiple diagnostic criterias has led to controversy on how to identify the patients with metabolic syndrome.

Variations in prevalence of the metabolic syndrome have been noted while using different criterias.

Prevalence of metabolic syndrome has been found to be different in different studies, depending on the population studied and the diagnostic criteria used. With the increasing prevalence of obesity, the prevalence of metabolic syndrome is increasing worldwide. Studies have reported a prevalence rate ranging from 10 to $84 \%$ in various populations [7].

It has been estimated that one-quarter of the world's population may be having metabolic syndrome [8].

The prevalence of metabolic syndrome in type 2 diabetic patients has been found to be between $57-92 \%$ in different studies, in different geographic locations.

\section{Aims and Objectives}

1. To establish the prevalence of metabolic syndrome in patients attending the outpatient department of Karnataka Institute of Diabetology, Bangalore.

2. To compare the prevalence of metabolic syndrome using modified NCEP ATP III and IDF criteria.

3. To compare the prevalence of metabolic syndrome in women and men.

4. To look for age specific prevalence of metabolic syndrome.

\section{Methodology}

A cross sectional study was done at Karnataka Institute of Diabetology, Bangalore from December 2014 to July 2015. All type 2 diabetic patients between the age group of $20-80$ years were included in the study. Type 1 diabetic subjects were excluded from the study. The study population consisted of 402 subjects, including 247 men and 155 women. After obtaining informed consent from the subjects, fasting blood sugar \& fasting lipid profile were measured in all subjects. Waist circumference was measured as the smallest horizontal girth between the costal margins \& iliac crests at minimal respiration. Blood pressure was recorded in sitting position, in the right arm, using the mercury sphygmomanometer. Modified NCEP ATP III criteria $\&$ IDF criteria were used to calculate the prevalence of metabolic syndrome (table 1).

\section{Results}

402 subjects were included in the study, with 247 (61.4\%) men and 155 (38.6\%) women. The subjects were in the age group of 20 - 80 years, with maximum number of subjects being in the age group of 41 - 50 and 51 - 60 years (table 2). The mean values of various metabolic parameters in the study population are shown in table 3 .

Table-1: Criteria's used in the study for diagnosis of metabolic Syndrome [5]

\begin{tabular}{|c|c|c|}
\hline Criteria & Modified NCEP ATP III (2004) & IDF (2005) \\
\hline Essential Criteria & $\geq \mathbf{3}$ of the following: & $\begin{array}{c}\text { Central obesity (see below) } \\
\text { And } \geq \mathbf{2} \text { of the following: }\end{array}$ \\
\hline Fasting Blood Glucose (mg/dl) & $\geq 100$, or $\mathrm{T} 2 \mathrm{DM}$ or treatment & $\geq 100$ or $\mathrm{T} 2 \mathrm{DM}$ diagnosis \\
\hline Waist circumference (WC) & $\begin{array}{c}>102 \mathrm{~cm} \text { in males } \\
\text { Or }>88 \mathrm{~cm} \text { in females }\end{array}$ & $\begin{array}{c}\geq 90 \mathrm{~cm} \text { in males } \\
\text { Or } \geq 80 \mathrm{~cm} \text { in females }\end{array}$ \\
\hline Blood Pressure (mm of $\mathrm{Hg}$ ) & $\geq 130 / 85$, or treatment & $\geq 130 / 85$, or treatment \\
\hline Triglyceride (mg/dl) & $\geq 150$, or treatment & $\geq 150$, or treatment \\
\hline High Density Lipoprotein (mg/dl) & $\begin{array}{l}<40 \text { in males } \& \\
<50 \text { in females }\end{array}$ & $\begin{array}{c}<40 \text { in males } \& \\
<50 \text { in females or treatment }\end{array}$ \\
\hline
\end{tabular}

A low level of high-density lipoprotein (HDL) was found in $62 \%$ of men and $84 \%$ of women. High triglycerides were seen in $45 \%$ of men and $43 \%$ women. Hypertension was seen in $69.2 \%$ of men and $86 \%$ women. The waist 
circumference (WC) was $>102 \mathrm{~cm}$ in $14.2 \%$ men and $>88 \mathrm{~cm}$ in $64 \%$ women. The $\mathrm{WC}$ was $>90 \mathrm{~cm}$ in $77 \%$ men and $>80$ $\mathrm{cm}$ in $95.4 \%$ women (table 4). Overall, low HDL was seen in $283(70 \%)$ subjects, high triglycerides in $178(44 \%)$ subjects and hypertension in $305(76 \%)$ subjects. The waist circumference was abnormal in $155(38.55 \%)$ subjects by modified NCEP-ATP III criteria and $306(76.11 \%)$ by IDF criteria.

Table-2: Baseline characteristics of the study population

\begin{tabular}{|c|c|c|c|c|c|}
\hline Parameter & & \multicolumn{2}{|c|}{ Number } & \multicolumn{2}{|c|}{ Percentage (\%) } \\
\hline \multirow[t]{3}{*}{ Number of patients } & Total & \multicolumn{2}{|c|}{402} & \multicolumn{2}{|c|}{100} \\
\hline & Men & \multicolumn{2}{|c|}{247} & \multicolumn{2}{|c|}{61.4} \\
\hline & Women & \multicolumn{2}{|c|}{155} & \multicolumn{2}{|c|}{38.6} \\
\hline \multirow[t]{2}{*}{ Age } & Men & \multicolumn{4}{|c|}{$54.05 \pm 11.44$ years } \\
\hline & Women & \multicolumn{4}{|c|}{$53.23 \pm 9.7$ years } \\
\hline \multirow[t]{8}{*}{ Age distribution of patients } & Years & Men & Women & Men & Women \\
\hline & $81-90$ & 3 & $1 \%$ & 1 & $0.6 \%$ \\
\hline & $71-80$ & 14 & $7 \%$ & 6 & $4 \%$ \\
\hline & $61-70$ & 55 & $18 \%$ & 22 & $12 \%$ \\
\hline & $51-60$ & 84 & $62 \%$ & 34 & $62 \%$ \\
\hline & $41-50$ & 57 & $54 \%$ & 23 & $54 \%$ \\
\hline & $31-40$ & 29 & $11 \%$ & 12 & $11 \%$ \\
\hline & $21-30$ & 5 & $2 \%$ & 2 & $2 \%$ \\
\hline
\end{tabular}

Table-3: Metabolic Characteristics of the study population

\begin{tabular}{|c|c|c|}
\hline Parameter & Men & Women \\
\hline Waist Circumference (cms) & $93.36 \pm 11.24$ & $93.64 \pm 9.1$ \\
\hline Systolic Blood Pressure (mm of Hg) & $148.2 \pm 16.23$ & $132 \pm 20.9$ \\
\hline Diastolic Blood Pressure (mm of Hg) & $89.29 \pm 51.94$ & $166 \pm 78.61$ \\
\hline Fasting Blood Glucose (mg/dl) & $191.24 \pm 69.5$ & $39.3 \pm 10.07$ \\
\hline High Density Lipoprotein (HDL) $(\mathrm{mg} / \mathrm{dl})$ & $39.01 \pm 16.67$ & $162 \pm 106.6$ \\
\hline Triglycerides $(\mathrm{TG})(\mathrm{mg} / \mathrm{dl})$ & $168.49 \pm 115.23$ & \\
\hline
\end{tabular}

Table-4: Prevalence of individual components of Metabolic Syndrome

\begin{tabular}{|c|c|c|c|c|c|c|c|c|}
\hline & \multicolumn{3}{|c|}{ Men (n- 247) } & \multicolumn{4}{c|}{ Women (n- 155) } \\
\hline & NCEP & \% & IDF & \% & NCEP & \% & IDF & \% \\
\hline Low HDL & 153 & 62 & 153 & 62 & 130 & 84 & 130 & 84 \\
\hline High Triglycerides & 111 & 45 & 111 & 45 & 67 & 43 & 67 & 43 \\
\hline Hypertension & 171 & 69.2 & 171 & 69.2 & 134 & 86 & 134 & 86 \\
\hline High Waist Circumference & 35 & 14.2 & 158 & 64 & 120 & 77 & 148 & 95.4 \\
\hline
\end{tabular}

Table-5: Number of criteria's in subjects with Metabolic Syndrome

\begin{tabular}{|c|c|c|c|c|c|c|c|c|}
\hline \multirow{2}{*}{ No } & \multicolumn{4}{|c|}{ Men (n- 247) } & \multicolumn{3}{c|}{ Women (n- 155) } \\
\cline { 2 - 10 } & \multicolumn{2}{|c|}{ IDF } & \multicolumn{2}{c|}{ NCEP } & \multicolumn{3}{c|}{ IDF } & \multicolumn{3}{c|}{ NCEP } \\
\hline & Number & Percent & Number & Percent & Number & Percent & Number & Percent \\
\hline 5 & 33 & 24.8 & 7 & 4.6 & 50 & 35.2 & 39 & 26.7 \\
\hline 4 & 57 & 42.9 & 65 & 42.2 & 70 & 49.4 & 77 & 52.7 \\
\hline 3 & 43 & 32.3 & 82 & 53.2 & 22 & 15.4 & 30 & 20.6 \\
\hline
\end{tabular}


Table-6: Prevalence of Metabolic Syndrome

\begin{tabular}{|c|c|c|c|c|c|c|}
\hline \multirow{2}{*}{} & \multicolumn{2}{|c|}{ TOTAL (n- 402) } & \multicolumn{2}{c|}{ Men (n-247) } & \multicolumn{2}{c|}{ Women (n-155) } \\
\cline { 2 - 7 } & Number & Percent & Number & Percent & Number & Percent \\
\hline NCEP & 300 & $75.1 \%$ & 154 & $62 \%$ & 146 & $94 \%$ \\
\hline IDF & 275 & $68 \%$ & 133 & $54 \%$ & 142 & $92 \%$ \\
\hline
\end{tabular}

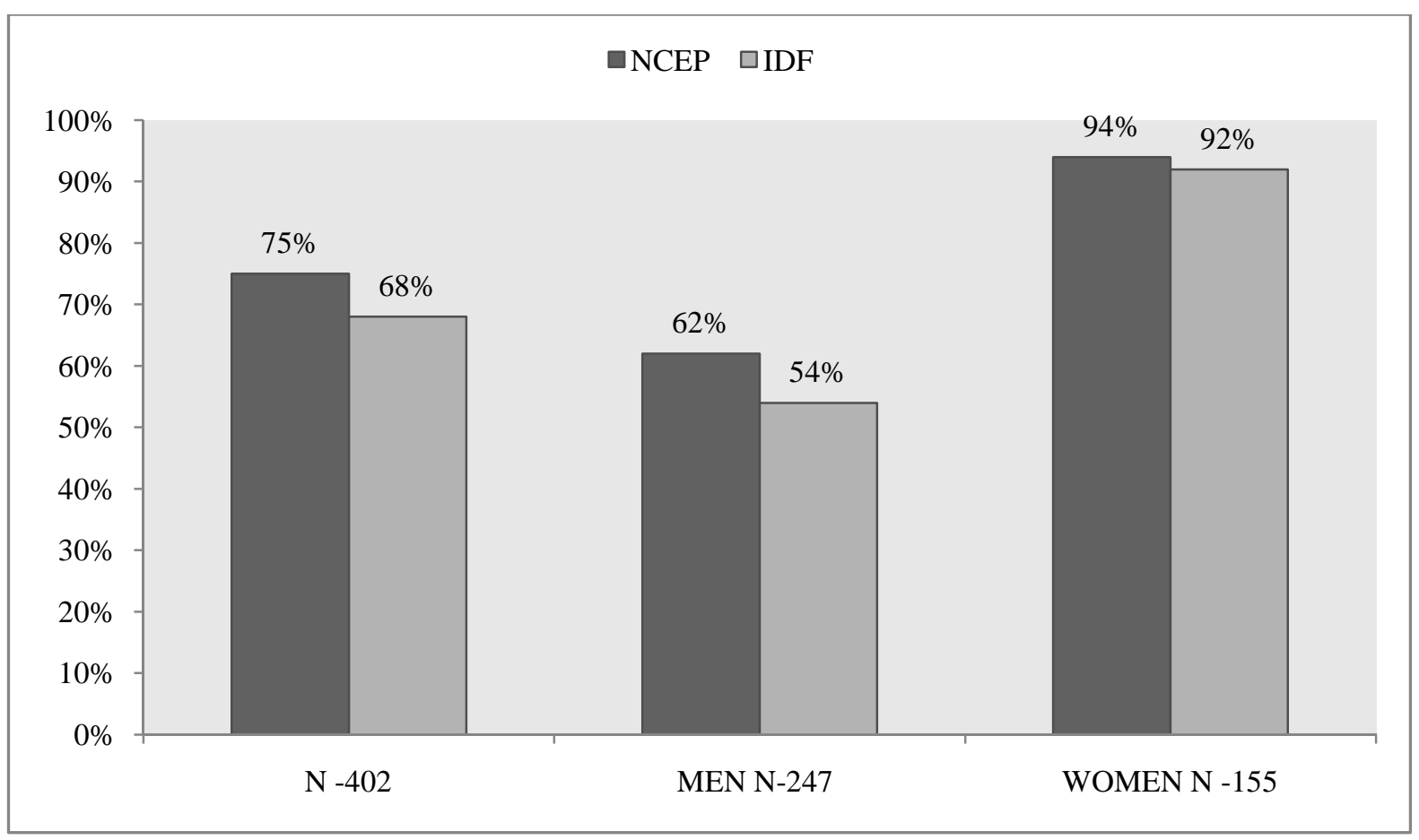

Figure-1: Prevalence of Metabolic Syndrome

In men, $24.8 \%$ patients had all the 5 components of metabolic syndrome, $42.9 \%$ had 4 components, and $32.3 \%$ had 3 components by IDF criteria, while only $5 \%$ had 5 components, $42 \%$ had 4 components, 53\% had 3 components by modified NCEP-ATP III criteria. In women, $35.2 \%$ had 5 components, $49.4 \%$ had 4 components, and $15.4 \%$ had 3 components by IDF criteria while $26.7 \%$ had 5 components, $52.7 \%$ had 4 components, $20.6 \%$ had 3 components by modified NCEP-ATP III criteria (table 5).

The prevalence of metabolic syndrome as estimated by modified NCEP ATP III criteria was $\mathbf{7 5 . 1 \%}$ while by IDF criteria it was $\mathbf{6 8 \%}$. The prevalence in women was $\mathbf{9 4 \%}$ by Modified NCEP ATP III criteria and $\mathbf{9 2 \%}$ by IDF criteria. The prevalence in men was $\mathbf{6 2 \%}$ by modified NCEP ATP III criteria and $\mathbf{5 4 \%}$ by IDF criteria (table 6 ; figure 1). Age related prevalence was not evident in this population.

\section{Discussion}

With increasing occurrence of metabolic risk factors, the prevalence of metabolic syndrome is increasing worldwide. Numerous studies have been conducted in different populations and disease states, linking metabolic syndrome to various adverse health outcomes. In the National Health and Nutrition Examination Survey III, the prevalence of metabolic syndrome among 8814 US adults was $33.7 \%$ in men and $35.4 \%$ in women by NCEP- ATP III criteria, while it was $39.9 \%$ in men $\& 38.1 \%$ in women by IDF criteria [9]. The Chennai Urban Rural Epidemiology Study found a prevalence rate of $23.2 \%$ by WHO criteria, $18.3 \%$ by ATP- III criteria, and $25.8 \%$ by IDF criteria [10]. The Indian atherosclerosis research study done with 2318 individuals, found that the prevalence of metabolic syndrome was $40.3 \%$ by ATP-III criteria, $30.6 \%$ by WHO criteria and $34.9 \%$ by IDF criteria [11]. A study of 495 subjects in rural Karnataka, found a 
prevalence of $20.52 \%$ by IDF criteria and $17.76 \%$ by modified NCEP ATP - III criteria [12].

Several studies have found higher prevalence of metabolic syndrome in type 2 Diabetes also. A study of 218 type-2 diabetic patients demonstrated that metabolic syndrome was present in $25.2 \%$ of the study population and was associated with a higher risk of stroke, peripheral vascular disease, and microalbuminuria [13]. In the NHANES III Study, the prevalence of metabolic syndrome was $86 \%$ in diabetic patients compared to $26 \%$ in euglycemic subjects [14]. In an Iranian study of 9889 diabetic subjects, the prevalence of metabolic syndrome was $65.0 \%$, with higher rate in females and in older age [15]. A study of 308 patients with type 2 diabetes in Cameroon showed that the prevalence of metabolic syndrome was $71.7 \%$ according to the IDF criteria and $60.4 \%$ according to NCEP-ATP III criteria. The prevalence was significantly higher in women than in men [16]. A cross-sectional study involving 700 type 2 diabetic subjects from Gwalior, India showed that the prevalence of metabolic syndrome was $45.8 \%, 57.7 \%$ and $28 \%$ according to NCEP-ATP III Criteria, IDF and WHO definitions, respectively. Again, the prevalence was higher in women in all age groups [17]. These studies prove that the prevalence of metabolic syndrome is higher in general population and further higher in population with diabetes.

In a study in Ghana, hypertension (60\%) was found to be the commonest component of metabolic syndrome, followed by central obesity $(48.67 \%)$, low HDL $(41.33 \%)$ and high triglycerides $(32.67 \%)$. In males, the most frequent component was hypertension, followed by hypertriglyceridemia and then low HDL. On the other hand, in females, the commonest component was central obesity, followed by low HDL, high triglycerides and lastly hypertension [18]. In another study from Ghana, hypertension was found to be the commonest component of metabolic syndrome, followed by hypertriglyceridemia [19].

Many of the studies like AusDiab study [20], DECODE study [21] and San Antonio Study [22] have highlighted the fact that different criterias arrive at different prevalence rates. Compared to WHO criteria, NCEPATP III Criteria has lower diagnostic threshold for HDL and hypertension, but higher threshold for obesity. Compared to NCEP-ATP III Criteria, IDF criteria has lower threshold for raised waist circumference and has central obesity as its essential criteria. These diversities would contribute to the disparity in prevalence rates for metabolic syndrome.

Our study also had similar findings. All the components of metabolic syndrome were found to be very common in type 2 diabetic subjects. High percentage of diabetic patients had multiple components of metabolic syndrome and $\approx 50 \%$ of the subjects had 4 components, $\approx 30 \%$ had 3 components and $\approx 25 \%$ had all 5 components. Among men, hypertension was the most common component, followed by central obesity defined by high waist circumference, low HDL and high triglycerides. Among women, high waist circumference was the most common component, followed by hypertension, low HDL and lastly high triglycerides. Overall, central obesity and hypertension were the commonest components of metabolic syndrome, followed by low HDL and high triglycerides in this diabetic representative population.

Using both criteria's, prevalence of metabolic syndrome was very high in this study population. Despite of IDF criteria having lower cut off for waist circumference, it identified lesser patients with metabolic syndrome, since central obesity is an essential component in IDF criteria. The difference is more evident in men. Women had significantly higher prevalence of metabolic syndrome, due to the higher prevalence of central obesity in them. The higher prevalence of metabolic syndrome is comparable or even higher than the above mentioned studies. The contribution of socio-economic status, physical activity, and rural- urban location to this prevalence rate would be a point of interest.

\section{Conclusions}

The prevalence of metabolic syndrome is significantly higher in our study population consisting of subjects with type 2 diabetes. The prevalence of metabolic syndrome is higher using modified NCEP-ATP III criteria compared to IDF criteria. The prevalence of metabolic syndrome is significantly higher in women.

Hence, it is imperative to screen subjects with diabetes for all the components of metabolic syndrome and recommend intensive lifestyle measures to avoid these metabolic risk factors in them. The findings also underline the need for unified diagnostic criteria for metabolic syndrome. This is necessary for achieving standardization in identification of subjects at high risk of CHD and Type 2 diabetes. 


\section{Abbrevations}

AHA: American Heart Association

CHD: Coronary Heart Disease

FBG: Fasting Blood Glucose

HDL: High Density Lipoprotein

IDF: International Diabetes Federation,

NCEP -ATP III: National Cholesterol Education Program - Adult Treatment Panel III

T2DM: Type 2 Diabetes

WC: Waist Circumference

WHO: World Health Organization

Funding: Nil, Conflict of interest: None initiated, Permission from IRB: Yes

\section{References}

1. Enzi G, Busetto L, Inelmen EM, Coin A, Sergi G. Historical perspective: visceral obesity and related comorbidity in Joannes Baptista Morgagni's 'De sedibus et causis morborum per anatomen indagata. Int $\mathrm{J}$ Obes Relat Metab Disord. 2003 Apr; 27(4):534-5.

2. Reaven GM. Role of Insulin Resistance in Human Disease Diabetes Dec. 1988; 37 (12): 1595-1607. doi: 10.2337/diab.37.12.1595.

3. Eckel RH, Grundy SM, Zimmet PZ. The metabolic syndrome. The Lancet. 2005 Apr 22; 365(9468):141528. http://dx.doi.org/10.1016/S0140-6736(05)66378-7

4. Isomaa BO, Almgren $\mathrm{P}$, Tuomi T, Forsén $\mathrm{B}$, Lahti K, Nissén M, Taskinen MR, Groop L. Cardiovascular morbidity and mortality associated with the metabolic syndrome. Diabetes Care 2001 Apr; 24(4): 683-689. http://dx.doi.org/10.2337/diacare.24.4.683.

5. Stern MP, Williams K, González-Villalpando C, Hunt KJ, Haffner SM. Does the metabolic syndrome improve identification of individuals at risk of type 2 diabetes and/or cardiovascular disease? Diabetes Care 2004 Nov; 27(11): 2676-2681. http://dx.doi.org/ 10.2337/diacare.27.11.2676.

6. Huang PL. A comprehensive definition for metabolic syndrome. Disease Models \& Mechanisms. 2009; 2(56): 231-237. doi:10.1242/dmm.001180.

7. Kaur J. A Comprehensive Review on Metabolic Syndrome. Cardiology Research and Practice. 2014; 2014:943162. doi:10.1155/2014/943162.
8. International Diabetes Federation: The IDF consensus worldwide definition of the metabolic syndrome. http: // www. idf. org/ metabolicsyndrome.

9. Ford ES, Giles WH, Dietz WH. Prevalence of the Metabolic Syndrome Among US Adults: Findings From the Third National Health and Nutrition Examination Survey. JAMA.2002; 287 (3):356-359. doi: 10.1001/ jama. 287.3.356.

10. Mohan V, Shanthirani S, Deepa R, Premalatha G, Sastry NG, Saroja R. Intra-urban differences in the prevalence of the metabolic syndrome in southern India - the Chennai Urban Population Study (CUPS No. 4). Diabetic Medicine, 2001; 18: 280-287. doi:10.1046/j. 1464-5491.2001.00421.x

11. Kanjilal S, Shanker J, Rao VS, et al. Prevalence and component analysis of metabolic syndrome: An Indian atherosclerosis research study perspective. Vascular Health and Risk Management. 2008; 4 (1):189197.

12. Kempegowda P, Marcus SR, Solanki $\mathrm{P}$ et al. Prevalence of the metabolic syndrome in rural India- a disparity in definitions. Int $\mathbf{J}$ Diabetes Dev Ctries (2011) 31: 188. doi:10.1007/s13410-011-0046-y

13. Alebiosu CO, Odusan BO. Metabolic syndrome in subjects with type-2 diabetes mellitus. Journal of the National Medical Association. 2004; 96(6):817-821.

14. Alexander CM, Landsman PB, Teutsch SM, Haffner SM. NCEP-defined metabolic syndrome, diabetes, and prevalence of coronary heart disease among NHANES III participants age 50 years and older. Diabetes. 2003 May; 52 (5): 1210-1214. http: //dx. doi. org /10.2337/ diabetes. 52.5.1210.

15. Janghorbani M, Amini M. Metabolic syndrome in type 2 diabetes mellitus in Isfahan, Iran: prevalence and risk factors. Metab Syndr Relat Disord. 2007 Sep; 5(3):243-54. doi: 10.1089/met.2005.0010.

16. Kengne AP, Limen SN, Sobngwi E, Djouogo CF, Nouedoui C. Metabolic syndrome in type 2 diabetes: comparative prevalence according to two sets of diagnostic criteria in sub-Saharan Africans. Diabetology \& Metabolic Syndrome. 2012; 4:22. doi: 10.1186/17585996-4-22. 
17. Yadav D, Mahajan S, Subramanian SK, Bisen PS, Chung CH, Prasad G. Prevalence of Metabolic Syndrome in Type 2 Diabetes Mellitus Using NCEPATPIII, IDF and WHO Definition and Its Agreement in Gwalior Chambal Region of Central India. Global Journal of Health Science. 2013; 5(6):142-155. doi:10.5539/gjhs.v5n6p142.

18. Nsiah K, Shang VO, Boateng KA, Mensah F. Prevalence of metabolic syndrome in type 2 diabetes mellitus patients. Int J App Basic Med Res, 2015; 5(2):133-138.

19. Nsiah K, Shang VO, Boateng KA, Mensah F. Prevalence of metabolic syndrome in type 2 diabetes mellitus patients. International Journal of Applied and Basic Medical Research. 2015; 5(2):133-138. doi:10. 4103/2229-516X.157170.
20. Cameron AJ, Magliano DJ, Zimmet PZ, Welborn TA, Colagiuri S, Tonkin AM, Shaw JE. The metabolic syndrome as a tool for predicting future diabetes: the AusDiab study. Journal of Internal Medicine, 264: 177186. doi:10.1111/j.1365-2796.2008.01935.x

21. Hu G, Qiao Q, Tuomilehto J, et al. Prevalence of the Metabolic Syndrome and Its Relation to All-Cause and Cardiovascular Mortality in Nondiabetic European Men and Women. Arch Intern Med. 2004; 164(10):10661076. doi:10.1001/archinte.164.10.1066.

22. Hunt KJ, Resendez RG, Williams K, Haffner SM, Stern MP. National Cholesterol Education Program versus World Health Organization metabolic syndrome in relation to all-cause and cardiovascular mortality in the San Antonio Heart Study. Circulation, 2004; 110(10):1251-7. doi: 10.1161/01.CIR.0000140762. 04598.F9.

\section{How to cite this article?}

Shetty S.B, Lalitha R, Kumar R.A.Diverse criteria's-disparate prevalence rates: prevalence of metabolic syndrome by modified NCEP-ATP III and IDF criteria.Int J Med Res Rev 2016;4(10):1731-1737.doi:10.17511/ijmrr. 2016.i10.03. 